\title{
Irregular rhythm?
}

\section{A. W. G. J. Oomen · F. F. J. Rozestraten}

An 84-year-old female presented with palpitations. Her cardiac medical history revealed persistent atrial fibrillation. The findings of a physical examination were normal. An electrocardiogram was recorded (Fig. 1). What is the rhythm and what is the mechanism for the varying conduction?
Open Access This article is distributed under the terms of the Creative Commons Attribution 4.0 International License (http://creativecommons.org/licenses/by/4.0/), which permits unrestricted use, distribution, and reproduction in any medium, provided you give appropriate credit to the original author(s) and the source, provide a link to the Creative Commons license, and indicate if changes were made.

\section{Answer}

You will find the answer elsewhere in this issue.

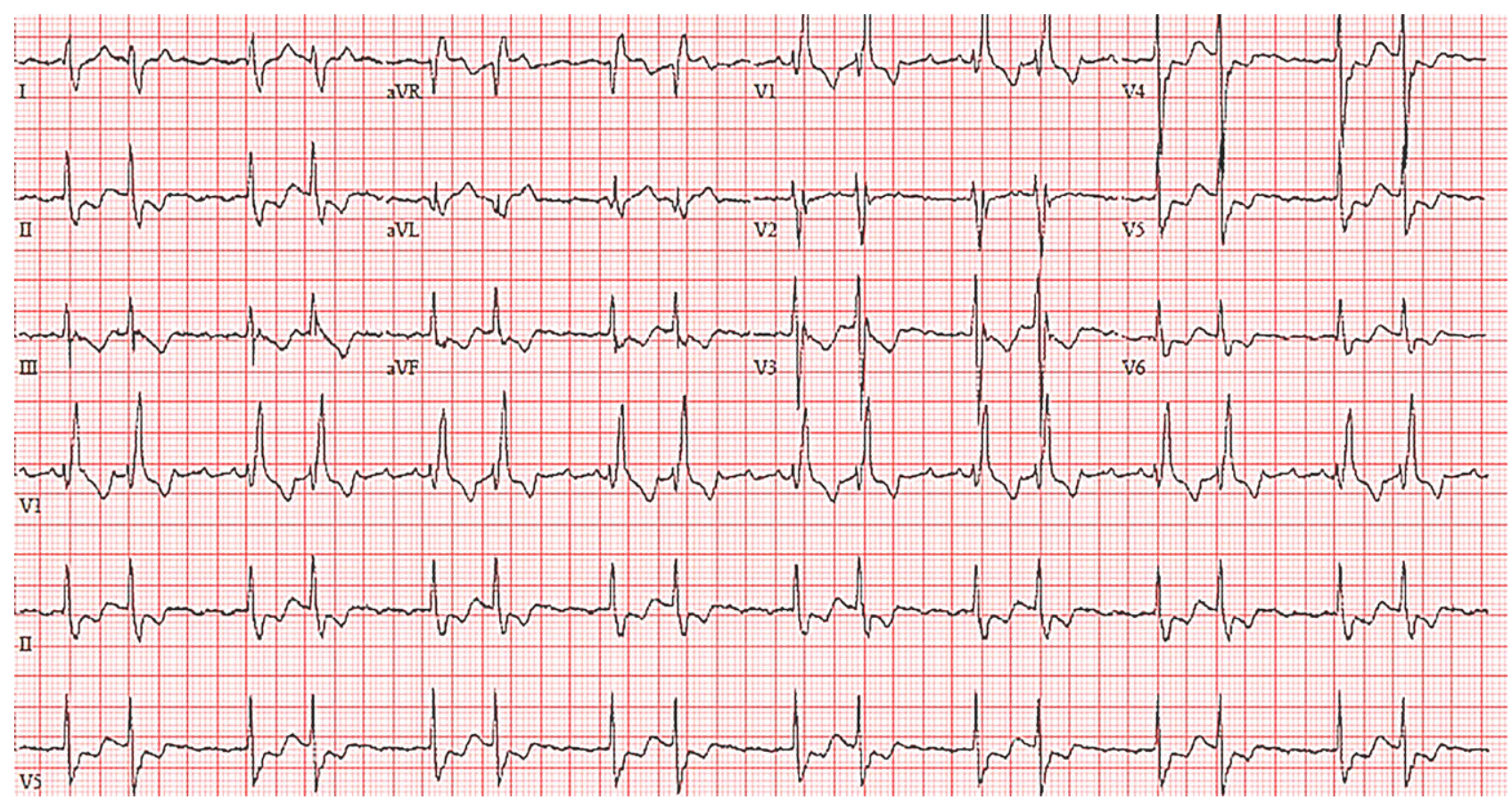

Fig. 1 Electrocardiogram at presentation

A. W. G. J. Oomen $(\bowtie)$

Department of Cardiology, Amphia Ziekenhuis, Breda, The Netherlands

AOomen5@amphia.nl
F. F. J. Rozestraten

Department of Cardiology, Catharina Ziekenhuis, Eindhoven, The Netherlands 